DOI 10.37882/2223-2982.2020.11.12

\title{
ФИЛОСОФСКО-ТЕОРЕТИЧЕСКИЕ АСПЕКТЫ ЕВРОПЕЙСКОЙ ИНТЕГРАЦИИ
}

\section{PHILOSOPHICAL AND THEORETICAL ASPECTS OF EUROPEAN INTEGRATION}

K. Dadashov

Summary: The article examines European foreign policy from the point of view of its three dimensions - historical, European and international. Considering the process of institutionalization of foreign policy cooperation of European states, the author focuses on the formation and development of the area of foreign and security policy (CFSP) and analyzes it through the prism of realism, neoinstitutionalism, intergovernmentalism and constructivism. In conclusion, the author notes that the $E U$ is a subject of the system of international relations of the XXI century; Although the Europeanization of the CFSP is lower than in other areas, significant progress has been made in the integration process, and the further development of the CFSP is driven by current external and security challenges.

Keywords: EU, common foreign and security policy, system of international relations, realism, neo-institutionalism, intergovernmentalism, constructivism.

\section{Введение}

$\ll \overline{5}$ удучи союзом 25 государств с населением более 450 млн человек, производящих четверть мирового национального продукта (ВНП), имея в распоряжении широкий набор инструментов, Европейский Союз неизбежно является глобальным игроком. Усиливающаяся конвергенция европейских интересов, укрепление взаимной солидарности делают ЕС все более серьезным, эффективным игроком. Европа должна быть готова разделить ответственность за безопасность в мире и строительство лучшего мира» [1].

Европейская внешняя политика состоит из трех измерений: первым является историческое измерение, в котором должно быть освещено, какие факторы привели к дальнейшему расширению и углублению этой области в ходе процесса европейской интеграции. Формирование европейского внешнеполитического сотрудничества, которое в то время все еще находилось за скобками институциональной структуры ЕС, в основном началось с создания в 1954 г. Западноевропейского союза, преследовавшего своей целью содействие интеграции Западной Германии как ФРГ, с одной стороны, и в связи с началом холодной войны укрепление либеральных демократий Западной Европы, противостоящим «народным демократиям» Восточной Европы,

\author{
Дадашов Кянан Камран оглы \\ Аспирант, Московский государственный институт \\ международных отношений МИД РФ (2. Москва) \\ Canan.94@mail.ru
}

Аннотация: В статье исследуется европейская внешняя политика с точки зрения трех ее измерений - исторического, европейского и международного. Рассматривая процесс институционализации внешнеполитического сотрудничества европейских государств, автор фокусируется на формировании и развитии области внешней политики и политики безопасности (ОВПБ) и анализирует ее через призму реализма, неоинституционализма, интерговернментализма и конструктивизма. В заключении автор отмечает, что ЕС является субъектом системы международных отношений XXI в.; хотя степень европеизации ОВПБ по сравнению с другими областями ниже, в процессе интеграции был достигнут значительный прогресс, а дальнейшее развитие ОВПБ обусловлено текущими внешними вызовами и проблемами безопасности.

Ключевые слова: ЕС, общая внешняя политика и политика безопасности, система международных отношений, реализм, неоинституционализм, интерговернментализм, конструктивизм.

которые находились в сфере влияния коммунистического СССР. В принципе его главная цель заключалась не в том, чтобы быть военным альянсом, поскольку политика безопасности в Европе в то время все еще была явно в компетенции НАТО, а пактом о поддержке, платформой для сотрудничества под руководством НАТО [2]. Только в начале 1970-х гг. был сделан институциональный шаг на пути координации внешней политики между европейскими государствами исключительно в рамках ЕС, а именно возникла Европейская политика соседства (ЕПС). Однако вплоть до середины 1980-х гг. возможности для сотрудничества государств-членов оставались рыхлыми, и только с имплементацией ЕЕА 1986 г. ЕПС была официально зафиксирована. Только в Маастрихтском договоре 1992 г. впервые была сформулирована общая внешняя политика и политика безопасности (ОВПБ) и закреплена в договорно обязательной форме. Это произошло в основном как прямая реакция на изменившуюся ситуацию в области безопасности после окончания конфликта между Востоком и Западом и зарождение угрожающих конфликтов в непосредственной близости от ЕC.

ОВПБ была впоследствии расширена в контексте содействия европейской интеграции в рамках Амстердамского, Ниццкого и Лиссабонского договоров, в которых были добавлены новые организационные структуры 
и уровни принятия решений. В процессе своего институционального расширения ОВПБ впервые добавила отдельный военный компонент с Ниццким договором. Общая политика безопасности и обороны (ОПБО) как неотъемлемая часть ОВПБ должна расширить ее путем добавления военных возможностей, тем самым усиливая и укрепляя потенциал ЕС для действий в международных миссиях [3].

Второе измерение, которое необходимо изучить, помимо исторического, -- европейское, что имеет решающее значение для внутриевропейской функциональности. В этом отношении ключевое значение имеют содержательные и аналитические расхождения с европейскими институтами, основными акторами и деятельностью ОВПБ. Помимо рассмотрения содержания ОВПБ до начала 1990-х гг., хронологические рамки исследования, в основном, охватывают промежуток между вступлением в силу Маастрихтского договора 1992 г. и подписанием Лиссабонского договора 2009 г. Прежде всего тот период занимает центральное место в институционализации ОВПБ, так как включает в себя все основные шаги в направлении интеграции и развития в этой области, и поэтому ему следует уделить особое внимание при анализе институционального аспекта ЕС.

Третье измерение - международное, поскольку оно является общей базой для внешней политики ЕС. Особенно в условиях идущей глобализации и одновременной интернационализации конфликтов по всему миру столь же важно осветить роль ЕС как актора в важнейших международных институтах в дополнение к анализу внутреннего развития ОВПБ в процессе европейской интеграции и возникающих проблемных областей. В этой связи особенно важны три международные организации: ООН, НАТО и ОБСЕ. В частности, эти три организации были выбраны для анализа, поскольку они являются ближайшими партнерами ЕС в нынешних горячих точках, урегулированием ситуации в которых занят сегодня Брюссель, будь то в соседних странах или на международном уровне в разных регионах мира.

Сотрудничество между ЕС и ООН начинается уже в начале 1960-х гг. с открытия информационного офиса ЕЭС в штаб-квартире ООН в Нью-Йорке. Уже в 1974 г. Европейскому сообществу был предоставлен статус наблюдателя ГА ООН [4], который включал установление постоянного дипломатического представительства ЕС в ООН в качестве первой международной организации. EC не только политически, но и финансово является важным партнером для ООН, поскольку, помимо единого представительства ЕС, все 27 государств - членов ЕС являются членами $\mathrm{OOH}$, в том числе $1 / 5$ обладает правом вето в СБ ООН, а также как сам ЕС в целом, так и его отдельные страны-члены ежегодно вносят значительные средства в бюджеты различных программ ООН. По сути, тесные отношения между ООН и ЕС основаны на общих целях и ценностях, которые были сформулированы как в $\mathrm{OOH}$, так и в ЕС и которые состоят в основном из общих гуманистических ценностей и миротворческих целей. Хотя системы ЕС и ООН принципиально несравнимы в институциональном плане, они являются международными субъектами, чьи методы работы и цели направлены на то, чтобы быть достигнутыми с помощью международного сообщества на основе международного сотрудничества.

Напротив, сотрудничество ЕС с НАТО в основном связано с безопасностью. Уже в первые дни существования ЕС в 1950-х гг. было установлено тесное сотрудничество с НАТО. Рамки стратегического партнерства, к которому стремятся две стороны, образуют декларация ЕС-НАТО о ЕПБО (2002) и «Соглашение Берлин+» (2003) [5]. Развитие ОПБО как самостоятельного компонента обороны ЕС не должно заменять НАТО, а дополнять его; однако, она должна уважаться также всеми странами ЕС, даже если они одновременно являются членами НАTO, и действовать независимо от альянса.

Таким образом, кооперация между ЕС и НАТО в рамках Соглашения Берлин + служит дополнением к структуре европейской безопасности, поскольку оно вовлекает в сотрудничество в области безопасности также и те европейские страны, которые являются членами НАТО, но не являются членами ЕС [6].

Еще одним близким партнером ЕС в Европе является ОБСЕ. Ее важность как партнёра ЕС по региональной безопасности особенно возросла после окончания конфликта между Востоком и Западом. Участниками данной организации являются все европейские страны, а также государства ЦА, за исключением Афганистана, и США.

Из-за своей многоуровневой структуры сложная сеть отношений ЕС в целом и особенно в области ОВПБ затрудняет работу над научным анализом с точки зрения одной теоретической школы. Поэтому для того, чтобы создать широкую теоретическую базу, необходимо прибегнуть к нескольким теориям. Только одна теоретическая школа не может полностью охватить многомерность субъекта. Такой сложный вопрос, как ОВПБ, не может быть адекватно объяснен лишь с помощью одного теоретического подхода особенно потому, что некоторые теоретические подходы в корне связаны с определенными историко-хронологическими факторами, т.е. они всегда возникают в контексте соответствующего им времени, в котором они возникли [7]. Исходя из эклектично-интегративного подхода, рассмотрим ОВПБ через призму четырех центральных школ мысли (реализм, неоинституционализм, интерговернментализм и конструктивизм). 


\section{(Нео)реализм}

Прежде всего, неореалистическая школа полезна для понимания соотношения сил и поведения акторов в системе международных отношений (CMO), в которую входят как государства - члены ЕС как национальные государства, так и теперь ЕС в целом. С реалистической точки зрения СМО понимается как анархическая система самопомощи, в которой прочная интеграция маловероятна, но выборочное сотрудничество все еще может иметь место между отдельными государствами-членами. В результате этой стратегии самопомощи государств усиливаются стимулы к сотрудничеству в целях стабилизации структур власти и компенсации её потери (как, например, после окончания холодной войны). Прежде всего, анархия в МО и международное распределение власти являются наиболее важными элементами реалистической школы, т.е. структура МО в отношении расклада сил явно определяется особенностями отдельных государств. Следовательно, эти особенности определяют структуру МО (включая полярность системы) и, в свою очередь, влияют на действия вовлеченных участников. Ввиду длящегося долгие годы процесса интеграции ЕС часто считается (с либерально-теоретической точки зрения), что классические реалистические школы МО с их основными тезисами больше не смогут объяснить европейскую систему. Центральная, по мнению реалистов, предпосылка действия суверенного государства больше не актуальна ввиду передачи полномочий наднациональной организации. Вначале не представляется правильным включить неореализм в качестве объяснительного элемента в теоретический анализ, однако с учётом эклектичного подхода в этой работе он может объяснить если не всю европейскую внешнюю политику, то хотя бы ее подобласть, а именно ОПБО.

С точки зрения неореализма, конец холодной войны, особенно в отношении ЕС, порождает новые стимулы для расширения гражданского, а также военного сотрудничества, особенно в связи с желанием многих европейских государств увеличить свой силовой потенциал по отношению к США как единственной оставшейся сверхдержаве и расширить собственную автономию от США в сфере безопасности. Трансформация СМО дала европейским государствам новые стимулы для изменения своего положения в рамках системы и переопределения их позиций в МО. Особенно мелкие государства видели преимущество в том, чтобы укрепить свое положение с помощью ЕС и приобрести значение как актор в МО. Сценарии угроз для отдельных стран также изменились (от классических межгосударственных конфликтов до усиления международного терроризма) и стали причиной расширения сотрудничества на основе рационального расчета затрат и выгод для всех стран - членов ЕС.

В результате роста интеграции в области сотрудни- чества по вопросам безопасности в последние годы неореалистичный подход в контексте сложной ситуации в мире в 1990-е гг. и начале XXI века способствует объяснению аспектов безопасности европейских внешних связей и институционального развития ОПБО. Особенно в контексте расширения международных военных миссий после имплементации ОПБО неореализм весьма иллюстративен.

В связи с этим неореализм в основном следует определенному объяснительному подходу -- «баланс сил» Кеннета Уолтца. Он означает, что все государства в СМО будут стремиться сами по себе создать такой баланс в раскладе сил, чтобы иметь возможность поддерживать свою власть по отношению к другим. В результате необходимо разработать стратегии самопомощи, особенно для небольших государств, с тем чтобы предотвратить возможное усиление других и таким образом сохранить баланс в МО. По этой причине европейские государства, игравшие второстепенную роль в биполярной системе во время холодной войны, где доминировали США и СССР, искали способ укрепить свои позиции в меняющейся международной системе. «Согласно теории баланса сил, другие страны, в одиночку или вместе, хотят уравновесить американскую мощь». Отсюда возникла основанная на рациональном расчете затрат и выгод необходимость сплочения в смысле расширения военного сотрудничества, которое дало слабым и мелким государствам возможность укрепить свои силы в новой СМО и обеспечить своё существование.

\section{(Нео)институшионализм}

Институционализм как теория взаимозависимости в принципе хорошо подходит для объяснения внешней политики ЕС, особенно ввиду того, что внешняя политика ЕС находится в сфере МП и расширенной системы ООН. Руководящим принципом является создание международных норм и структур на глобальном уровне, которые помогут избежать войны и обеспечить мирное урегулирование конфликтов. Взаимозависимость создается в этом случае посредством транснациональных связей. Следовательно, для национальных участников создаются стимулы для регулирования, сотрудничества, поведенческого контроля и наказания за нарушения правил. Таким образом, целенаправленное действие должно ограничивать использование военной мощи. Это уменьшает дилемму безопасности, поскольку государства теперь могут доказать свою силу не через военную мощь, а посредством конкурентоспособности в рамках МРT.

Вера в мирное межгосударственное урегулирование конфликта посредством участия межнациональных или наднациональных организаций в основном считается структурой более высокого уровня действий. Хотя конфликтов нельзя полностью избежать, создание моделей 
сотрудничества должно обеспечить мирное урегулирование конфликтов. Одним из руководящих принципов является «Function follows form»-- должны быть созданы политические организации, чтобы наконец прийти к социальной интеграции. Основной причиной этого является признание транснационализации в таких областях, как политика, экономика, связь и т. д. Поэтому необходимы основанные на неразрывной связи в социально-экономической области международное государственное сотрудничество, институциональное строительство и «всемирная внутренняя политика», которым должно быть противопоставлено адаптированное политическое управление посредством наднациональных организаций с целью поддержания управления за существующей системой. Таким образом, прогрессивная интернационализация на разных уровнях требует необходимого институционализма.

Таким образом, институционализм в анализе ОВПБ может использоваться в качестве объяснения для международного уровня европейской внешней политики. Основное внимание в анализе уделяется сотрудничеству ЕС с важными организациями МО. Прежде всего, сотрудничество с ООН рассматривается как руководящий принцип для целей внешней политики $\mathrm{EC}$, поскольку как $\mathrm{OOH}$, так и ЕС рассматривают ценности и принципы МП как основу для своих международных действий, которые заключаются в сотрудничестве в области международной помощи в целях развития и миротворчества. Но в других областях, таких как ОПБО, ЕС часто полагается на сотрудничество с НАТО и ОБСЕ в качестве своих основных партнеров. Эти формы сотрудничества служат увеличению сферы и факторов влияния на международном уровне, даже если это связано с определенной потерей автономии.

\section{Интерговернментализм}

Интерговернментализм как теоретический подход в основном разделен на две составляющие: реалистический (С. Хоффман) и либеральный (Э. Моравчик). Для детального анализа ОВПБ два варианта могут быть объяснительными, причём в этой работе упор делается главным образом на либеральный интерговернментализм Э. Моравчика. Реалистический интерговернментализм Хоффмана следует предположению, что государстваучастники процесса европейской интеграции в принципе являются главными акторами, и их правительства берут на себя посредническую роль на национальном и международном уровнях. При этом добиться прогресса в направлении интеграции и, таким образом, сотрудничества друг с другом можно, если достигнута конвергенция различных национальных интересов.

Либеральный интерговернментализм Моравчика, помимо реалистического подхода Хоффмана, предполагает, что национальные государства-субъекты играют центральную роль в формировании национальных предпочтений и, таким образом, оказывают значительное влияние на интеграционный процесс на европейском уровне: «Либеральная ТМО разрабатывает понимание, что отношения между государством и обществом - отношения государств к внутреннему и межнациональному социальному контексту, в который они включены - оказывают фундаментальное влияние на государственное поведение в мировой политике».

Моравчик утверждает, что правительства используют ОВПБ как инструмент для более эффективного достижения своих внешнеполитических целей и что наднациональные институты оказывают лишь очень ограниченное влияние на формулирование и осуществление общей внешней политики. Таким образом, этот подход определяется национальными интересами и межправительственными переговорами между членами. Эта способность вести переговоры между государствами лежит в основе сотрудничества в области внешней политики и безопасности в рамках ЕC, поскольку эта область политики была задумана как межправительственная в процессе интеграции, в отличие от других сфер политики европейского сотрудничества.

Либеральный интерговернментализм является одним из государствоцентричных подходов теорий интеграции и в основном предполагает, что государство, т.е. правительство, не только конкурирует с другими на международном уровне, но также должно заявлять о себе на национальном уровне в отношении конкурирующих субъектов. Таким образом, если государство является частью наднационального образования, такого как ЕС, правительство имеет определенный дуализм действий (национальный и европейский) и в лучшем случае понимает, как использовать два уровня для себя и своих интересов. Перенос определенных политик с национального на европейский уровень может увеличить власть, поскольку генерируются дополнительные ресурсы, которые укрепляют правительство внутри страны против своих национальных конкурентов.

Это также объясняет внешнеполитическое сотрудничество и выгоды, которые несёт ОВПБ, по крайней мере на международном уровне. Многим членам сотрудничество даёт существенное влияние, которого у них самих по себе, в частности у небольших государств, не было бы. Большие государства с сильным потенциалом довольно осторожны и скептически относятся к процессу коммунитаризации. Тем не менее, государства с большим количеством возможностей для маневра получают выгоду за счет сокращения своих расходов. Хотя ОВПБ как институт в своей нынешней форме не может ставить общих целей без согласия всех государств-членов, он обеспечивает основу для сотрудничества, которая снижает издержки и повышает доверие. Несмотря на свое 
сотрудничество, национальные государства остаются в основном конкурентами за международную власть и влияние, поэтому возможности для успешной общей внешней политики ограничены с самого начала. Кроме того, после окончания ХВ были созданы дополнительные стимулы для сотрудничества ЕС ввиду изменения CMO, в рамках которой Европа должна заявить о себе.

На европейском уровне еще один аргумент либерального интерговернментализма иногда занимает центральное место в анализе -- вопрос о степени интеграции в области ОВПБ, и здесь становится ясно, что либеральный интерговернментализм может достаточно хорошо его описать. Как уже упоминалось ранее, сотрудничество государств - членов ЕС в области внешней политики и безопасности по-прежнему характеризуется преимущественно сохраненным суверенитетом государств, т.е. хотя на европейском уровне существует некоторая форма сотрудничества, уровень интеграции остается низким из-за организационной структуры с сохранением национальных полномочий по принятию решений. Политическая область, созданная Маастрихтским договором как межправительственная, требует единогласия всех 27 государств-членов для принятия решений, что подразумевает, что если страна-член наложила вето, решение не принимается. К сожалению, этот аргумент также дает понять, что в основе процесса принятия решений ОВПБ лежит минимальный принцип, и поэтому его эффективность часто довольно слаба.

\section{Конструктивизм}

В этой работе используется конструктивистская теория Александра Вендта. Конструктивизм, как и реализм, в этой форме анализа служит объяснению структурного уровня государственного действия. Как и реализм, конструктивизм, по словам Вендта, соотносится со структурой МО как уровень анализа и объясняет «явления международной политики вне структуры СМО». Однако в центре анализа лежат не только материальные, но и нематериальные причины действий акторов. В своем теоретическом построении Вендт не рассматривает анархию МО как страдание, вместо этого, по его мнению, взаимодействие субъектов различных культурных традиций может быть использовано для получения моделей действий, которые влияют на поведение государств. Но для Вендта в его теоретической конструкции, центральна взаимосвязь между субъектами и структурами, которые сами себя обуславливают. С одной стороны, структуры влияют на действия акторов, с другой стороны, действия и характеристики участников определяют структуры, в которых они действуют. Эти структуры затем формируют рамки для социального взаимодействия акторов и не фиксируются с самого начала, но неоднократно воспроизводятся действиями акторов, с одной стороны, и меняются, с другой. Одно из его основных предположений состоит в том, что «международные институты действительно способны влиять на государственную идентичность и интересы».

Применительно к ЕС теперь можно сделать вывод, что конструктивные и рамочные условия ЕС и связанные с ними европейские ценности и цели оказывают положительное влияние на действия отдельных государств-членов и приводят их к общим действиям. Таким образом, конструктивизм может быть использован, в частности, для объяснения областей ОВПБ, в которых сильные личные интересы участников все больше полагаются на тесное сотрудничество в европейском контексте. Конструктивизм, таким образом, может быть особенно полезен при анализе того, почему государства-члены решили во многих областях передать свой национальный суверенитет и полномочия наднациональному уровню, тем самым отказавшись от своей собственной власти в этих сферах. Конструктивизм уделяет основное внимание не рациональным мотивам, а идентичности, ценностям и ролевым моделям, которые рассматриваются в качестве центральных факторов, влияющих на внешнюю политику EC, и, следовательно, являются определяющими для них, прежде всего, в формировании национальных интересов государств-членов.

Основное внимание уделяется анализу ЕС как нормативной силы в МО, особенно в отношении ценностной концепции внешней политики ЕС. Эти нормативные факторы по-прежнему являются фундаментом, который определяет внешние действия, и считаются центральными объяснительными факторами процесса интеграции в этой области. ЕС достигает своего предела как «нормативная сила», когда основанная на ценностях политика вступает в конкуренцию с национальными интересами.

Конструктивизм, таким образом, хорошо подходит для анализа ОВПБ в этой работе, поскольку он может объяснить, почему иногда выходит достичь хорошо слаженного сотрудничества в области внешней политики, а иногда нет, и какие нормативные факторы являются решающими в том или ином случае для успеха и неудачи.

Прежде чем начать с подробного анализа выбранной темы, нужно сначала кратко обсудить и определить различные термины, которые вытекают из предмета. Эти термины разграничены и адаптированы к рассматриваемой теме.

Европейская внешняя политика является одной из центральных и самых сложных политик ЕС. В принципе, европейские внешние действия подразделяются на разные сферы, некоторые из которых действуют на межправительственном уровне, а другие организованы на наднациональной основе и, как следствие, демонстрируют различную степень интеграции. Например, существуют такие области, как общая торговая политика, которая яв- 
ляется одной из старейших областей политики ЕС, указывающая своей наднациональной организацией на высокий уровень интеграции, и другие области, такие как ОВПБ или ОПБО, показывающие сравнительно низкий уровень интеграции на европейском уровне, поскольку они организованы на межправительственном уровне. В принципе, внешние действия ЕС делятся на три основные области: общая торговая политика, общая политика развития и ОВПБ. Внешняя политика ЕС основана на ценностях, т.е. внешние действия ЕС базируются на изложенных в Статье 2 Договора ЕС принципах демократии, верховенства закона, прав человека и основных свобод, солидарности, основных положений МП и Устава ООН [8].

Как уже упоминалось, внешние действия ЕС делятся на разные области. Неотъемлемой частью является общая торговая политика ЕС. Будучи одной из важнейших торговых держав и крупнейшим единым рынком в мире, не только внутренняя кооперация между странами-членами, но и глобальное экономическое сотрудничество с другими основными рынками мировой торговли были краеугольными камнями понимания самого ЕС. В частности, развитие конкурентоспособности и ключевых рынков осуществляется в основном посредством соглашений о свободной торговле [9]. Несмотря на центральное значение, эта область не рассматривается в определении европейской внешней политики, лишь ОВПБ отводится решающее значение. Другие сферы, такие как политика соседства ЕС и политика расширения, не включены или только незначительно включены в анализ.

Процесс европеизации начинается с Римских договоров 1954 г. Изначально задуманный как мирно-политический и экономический проект, на протяжении многих лет он шёл к более тесному политическому сотрудничеству на европейском уровне, которое также включает институционализацию и высокую степень юридической ответственности. Важно понимать этот процесс не как линейный, а как динамический, который преобладал в различных областях политики с различной степенью интеграции и различным временным горизонтом реализации. Клаудио Раделли внес важный вклад в определение европеизации в своей работе в начале 2000-х гг., пытаясь прояснить концепцию европеизации, чтобы лучше отличить ее от других терминов, таких как интеграция: «Европеизация состоит из процессов а) конструирования, б) распространения и в) институционализации формальных и неформальных правил, процедур, политических парадигм, стилей, способов ведения дел и общих убеждений и норм, которые впервые определены и консолидируются в ЕС, а затем включены в логику внутреннего (национального и субнационального) дискурса, политических структур и государственной политики».

Он предполагает, что сотрудничество государств-чле- нов на европейском уровне в отдельных областях политики создает определенные модели действий, которые затем оказывают обратное воздействие на отдельные действия стран-членов, влияя на них и, таким образом, неизбежно приводят к ассимиляции. Такой подход можно наблюдать не только на европейском уровне, но и во внешних действиях ЕС с третьими странами, особенно когда речь идет о политике расширения ЕС или соглашениях об ассоциации с отдельными странами. В частности, в области переговорных стратегий должны быть предусмотрены стимулы, чтобы побудить третьи страны соблюдать и, в случае необходимости, принимать правила ЕС (особенно в области верховенства права, борьбы с коррупцией, прав человека), тем самым инициируя процессы ассимиляции, совпадающие с основными целями внешней политики ЕС, такими как продвижение демократии и стабильности, уважение прав человека и т.п.

СMO, с одной стороны, определяется межгосударственными отношениями, а с другой стороны, если шире, определяется как сеть разнообразных отношений, возникающих в результате взаимодействия государственных и негосударственных акторов. Это могут быть политические, экономические, культурные или военные отношения, которые могут возникнуть между национальными государствами, международными или наднациональными организациями. В результате более широкого толкования акторности субъектов, действующих в СМО, к ним причисляются не только отдельные национальные государства, но также и международные организации, такие как ООН или ЕС. Актор -- это действующий в политике индивидуум или коллективный субъект (правительство, группы интересов), так что каждое государство и каждая организация, которая участвует в MO, является в основном актором СМO.

\section{Зак^ючение}

Подводя итог, можно сказать, что ЕС в его нынешней институциональной форме не только на европейском, но и на международном уровне является релевантным субъектом СMO XXI в. Хотя область внешней политики и политики безопасности имеет относительно низкую степень европеизации по сравнению с другими, за последние 20 лет был достигнут значительный прогресс в процессе интеграции. Принимая во внимание текущие внешние вызовы и проблемы безопасности, стоящие перед ЕС, мы увидим, в каком направлении пойдет дальнейшее развитие ОВПБ, потому что, как и большая часть EC, ОВПБ также является областью, процесс развития которой еще, а может и никогда не будет завершен. Процесс евроинтеграции с самого начала был асимметричным и часто проводился под влиянием внешних факторов -- аспекта, который также затронул ОВПБ, и, таким образом, будет видно, могут ли текущие проблемы стать еще одним импульсом в этой области. 


\section{ЛИТЕРАТУРА}

1. Европейская стратегия безопасности. Безопасная Европа в лучшем мире [Электронный ресурс] // Совет Европейского союза. - 2003. - 12 декабря. Режим доступа: https://www.consilium.europa.eu/media/30825/qc7809568ruc.pdf

2. Westeuropäische Union (WEU). [Электронный ресурс]. Режим доступа:https://www.bpb.de/nachschlagen/lexika/politiklexikon/18478/westeuropaeischeunion-weu

3. Gemeinsame Sicherheits- und Verteidigungspolitik (GSVP). [Электронный ресурс]. Режим доступа: https://www.bpb.de/nachschlagen/lexika/177003/ gemeinsame-sicherheits-und-verteidigungspolitik-gsvp

4. The General Assembly, wishing to promote co-operation between the United Nations and the European Economic Community, requests the Secretary-general to invite the European Economic Community to participate in the sessions and work of the General Assembly in the capacity of observer. General Assembly Plenary meeting 11 0ctober, 1974[Электронный ресурс]. Режим доступа: http://www.daccess-ods.un.org/TMP/797562.301158905.html

5. Howorth Jolyon (2011) The EU's Security and Defence Policy: Towards Strategic Approach. In: Hill, Christopher/ Smith, Michael (eds.) (2011) International Relations and the European Union. 2nd Edition. Oxford University Press. P. 205

6. Permanent Delegation of the Federal Republic of Germany to the North Atlantic Treaty Organization. [Электронный ресурс]. Режим доступа: https://nato.diplo. de/Vertretung/nato/de/04/Zusammenarbeit_EU/Zusammenarbeit_20mit_20der_\%2020EU.html

7. Höll, Otmar (2014) : Vorlesung M4: Internationale Politik, Universität Wien, Folie 41.

8. EU-Vertrag. Titel I - Gemeinsame Bestimmungen (Art. 1 - 8). [Электронный ресурс]. Режим доступа: https://dejure.org/gesetze/EU/2.html

9. Für offenen und fairen Welthandel. [Электронный ресурс]. Режим доступа: https://europa.eu/european-union/topics/trade_de

$$
\text { () Дадашов Кянан Камран оглы (Canan.94@mail.ru). }
$$

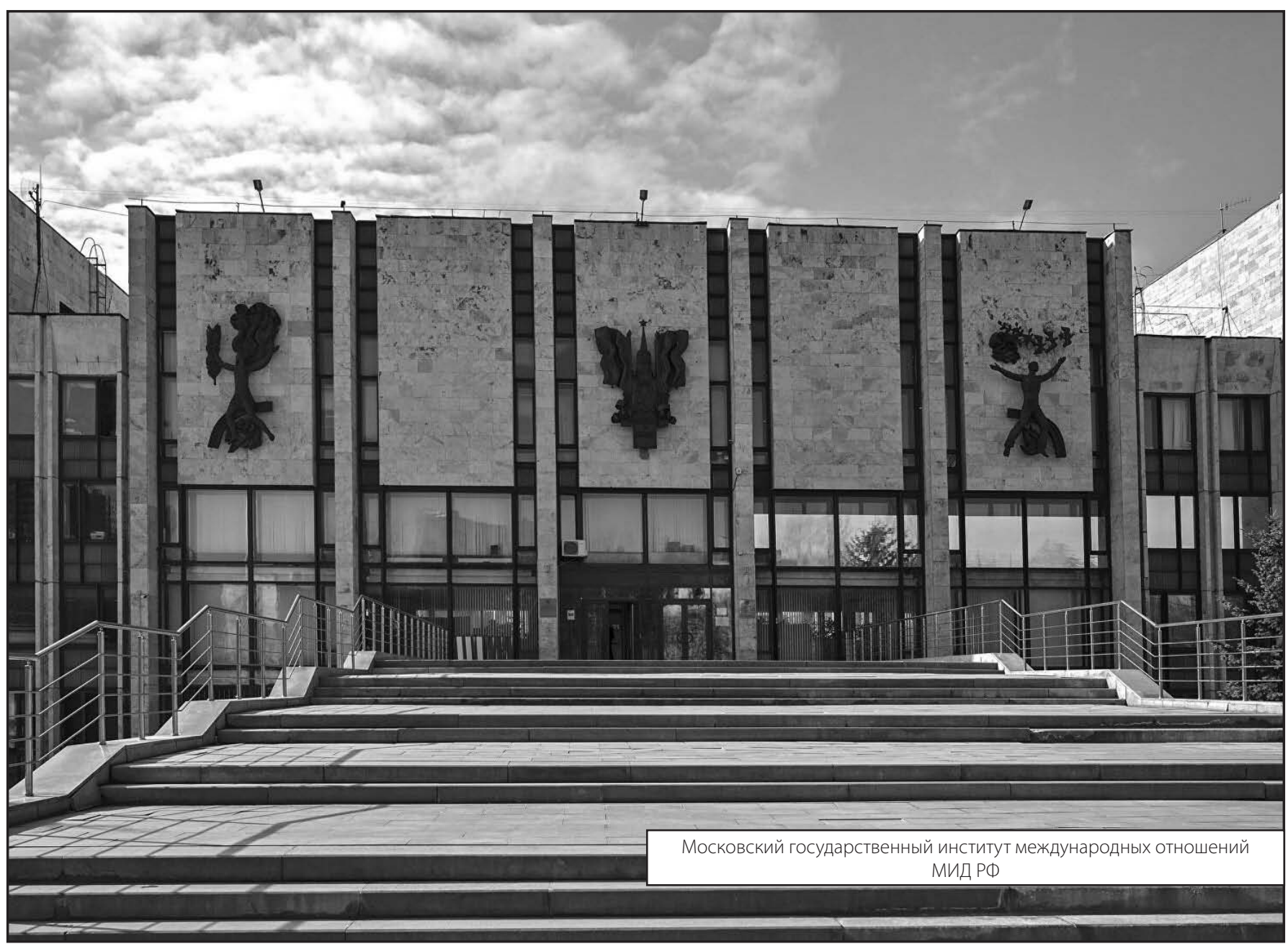

